\title{
Experimental and Theoretical Investigation of a Hybrid Compressor and Ejector Refrigeration System for Automotive Air Conditioning Application
}

\author{
Natthanan Keeratiyadathanapat ${ }^{\mathrm{a}}$, Thanarath Sriveerakul ${ }^{\mathrm{b}, *}$, Nat Suvarnakuta, \\ and Kulachate Pianthong \\ Department of Mechanical Engineering, Faculty of Engineering, Ubon Ratchathani University, \\ Ubon Ratchathani 34190, Thailand \\ E-mail: atanapatann@hotmail.com, bthanarat.s@ubu.ac.th (Corresponding author)
}

\begin{abstract}
In this research, performance of a hybrid compressor and ejector refrigeration system for automotive air conditioning application was investigated theoretically and experimentally. Mathematical modeling integrated the 1-dimensional analysis of ejector with the thermodynamic analysis of the hybrid compressor and ejector refrigeration system via EES (Engineering Equation Solver) software was proposed. Also an experimental rig of the hybrid compressor and ejector refrigeration system for automotive air conditioning application was built. This hybrid system has a rated cooling capacity of $3.5 \mathrm{~kW}$. Refrigerant R134a and R141b were used for mechanical vapor compression sub system and the ejector sub system, respectively. The operating conditions are chosen accordingly as, generator temperature between $100{ }^{\circ} \mathrm{C}$ and $120^{\circ} \mathrm{C}$, condenser temperature between $30^{\circ} \mathrm{C}$ and $40^{\circ} \mathrm{C}$, and evaporator temperature between $0{ }^{\circ} \mathrm{C}$ and $10^{\circ} \mathrm{C}$. Theoretical results of the ejector's entrainment ratio $(\mathrm{Rm})$ and COP of the system with variations on operating conditions were compared with the experiment values. From the results, mathematical modeling seems to provide error in COP prediction up to $15.5 \%$ when compared with experimental values. Fortunately, modification of the mathematical modeling by applying the computational fluid dynamics (CFD) technique provides less error about 5.5\%. It's also found that the COP of the hybrid system can be increased by $10-20 \%$ compared to a simple stage ejector refrigeration cycle (EJC). Moreover, estimated power consumption of the automotive air conditioning system can be approximately reduced $20 \%$ under the conventional vapor compression cycle.
\end{abstract}

Keywords: Ejector, combined ejector-vapour refrigeration system, performance analysis.

ENGINEERING JOURNAL Volume 21 Issue 5

Received 6 February 2017

Accepted 22 April 2017

Published 29 September 2017

Online at http://www.engj.org/

DOI:10.4186/ei.2017.21.5.105 


\section{Introduction}

Low temperature heat sources such as solar energy, waste heat, geothermal energy and exhaust gas of automobiles, exist in the world extensively [1], [2]. Ejector refrigeration cycle (EJC) utilizes such low temperature heat energy to generate cooling process [3-5]. Several advantages over vapor compression refrigeration systems are for example, no moving parts, little maintenance, long lifespan, and high reliability [6]. It can be used with versatile refrigerants such as water, R134a [7], R152a [8]. However, the coefficient of performance (COP) and the refrigeration capacity of the EJC are relatively small. In order to improve the COP of the EJC, analysis and experiment of the EJC have been researched over the past decades [6-10] and some new configurations based on the combined ejector refrigeration cycle with other existing cycles have also been proposed.

An equation study of the flow in one-dimensional (1D) model was first explained by Keenan et al. [11] about the continuity, momentum and energy equation of the ejector design principle. This model has been used as a theoretical foundation in ejector design long time ago. However, this model has been criticized for its lack of predicting the constant - capacity characteristic [12]. Following this, theoretical research on a hybrid compressor and ejector refrigeration system using refrigerant R142b and R134a was carried out by Hernandez et al. [9]. Variations on the temperature of the boiler and the heating coil were investigated in order to find the best operating temperature of the heat exchanger. The maximum COP of 0.48 (at exergy efficiency of 0.25 ) was found for the system operating with R134a, condenser and generator temperature of 30 and $85^{\circ} \mathrm{C}$. The temperature of the evaporator was at $10{ }^{\circ} \mathrm{C}$ and the cooling load was at $1 \mathrm{~kW}$.

Additionally, Rusly et al. [13] conducted a comparative study of one-dimensional (1D) and CFD analysis. CFD analysis results for the ejector's performance were validated with experimental data and produced a better agreement to experimental results than the 1D analysis. Recently, the simulation and optimization of a solar assisted combined ejector-vapour compression cycle for cooling applications were studied. The mechanical compression system used R134a as the working fluid and the ejector cycle with R141b. The economic optimized system was found to be a system with $10.5 \mathrm{~kW}$ cooling capacity with the combined COP of 0.89. [10]. These research studies are examples of the mathematical modelling of combined/hybrid ejector-vapour compression refrigeration cycle.

Among the very few research published in the literature, Jia Yan et al. [14] conducted an experiment of a combined ejector-vapor compression cycle. This cycle uses working fluid refrigerant R134a and air-cooled condensers for both sub-cycles. The test results showed that the performance of the combined cycle is very sensitive to the evaporating, generating and condensing temperatures of the ejector cycle. Improvements on the COP of the combined cycle were found to be $19.4 \%$ over the traditional vapor compression cycle. However, the combined system with the R134a (the high pressure refrigerant) for both sub-cycles requires carefully design of the system's component.

Due to the lack of research on combined theoretical and mathematical analysis with testing experiment, this paper focuses on theoretical study and experimental testing of a combined ejector refrigeration cycle with an automotive refrigeration cycle. This allows us to investigate the effects of the operating conditions including the generator condition on the performance of the system.

The generator of the system, as shown in Fig. 1, can be driven by waste heat from car exhaust. The temperature of the car exhaust gas is usually at the temperature between $240{ }^{\circ} \mathrm{C}$ and $480{ }^{\circ} \mathrm{C}$ [15-17].

\section{System Description}

\subsection{Working Fluids Selection}

In the present study, R141b and R134a were selected as the working fluid for the combined ejector-vapour compression refrigeration cycle. Since R134a refrigerant has been used extensively in vapor compression systems in automobiles. Thus, R134a refrigerants are used in vapor compression systems. However, the vapor pressure of R141b is lower than that of R134a. The R141b has also been considered as one of appropriated refrigerants for the EJC, due to its properties such as, high molecular weight, relatively low ODP and GWP. Table 1 shows the main properties of R134a and R141b. Although there are environmental friendly refrigerants with lower ODP and GWP than the R134a and 141b, they have not yet been easily found and available in the local market. For future work involving the experiment, special 
sealing materials also have to be considered when the replacement refrigerant rather than R134a and R141b were applied.



Fig. 1. Schematic diagram of a hybrid compressor and ejector refrigeration system.

Table 1. Properties of working fluid R141b and R134a.

\begin{tabular}{lcc}
\hline Physical properties & R141b & R134a \\
\hline Chemical formula & $\mathrm{CH}_{3} \mathrm{CC}{ }_{2} \mathrm{~F}$ & $\mathrm{CF}_{3} \mathrm{CH}_{2} \mathrm{~F}$ \\
Molecular weight & 116.95 & 102.03 \\
Boiling point under $1.013 \times 10^{5} \mathrm{~Pa}\left({ }^{\circ} \mathrm{C}\right)$ & 32.05 & -26.10 \\
Critical temperature $\left({ }^{\circ} \mathrm{C}\right)$ & 204.15 & 101.1 \\
Critical pressure $(\mathrm{MPa})$ & 4.25 & 4.059 \\
Critical density $\left(\mathrm{g} / \mathrm{cm}^{3}\right)$ & 0.43 & 0.52 \\
Vapor pressure at $25^{\circ} \mathrm{C}(\mathrm{kPa})$ & 79 & 666 \\
Latent heat at $0{ }^{\circ} \mathrm{C}(\mathrm{kJ} / \mathrm{Kg})$ & 129.4 & 190.9 \\
Global warming potential $(\mathrm{GWP})$ & 1.2 & 0.26 \\
Ozone depletion potential $(\mathrm{ODP})$ & 0 & 0.02 \\
\hline
\end{tabular}

\subsection{System Configuration}

A schematic diagram and P-h diagram of a combined ejector-vapour compression refrigeration cycle for automotive air conditioning is illustrated in Figs. 1 and 2. The system consists of the EJC (the upper cycle) and the vapour compression cycle (the lower cycle). The EJC utilizes waste heat energy from car exhaust to build a high pressure R141b in the generator (From 9 to 10). This high pressure or primary fluid will be expanded and accelerated through a primary nozzle of the ejector. Then, it fans out with supersonic speed to create a very low pressure region (vacuum) at the nozzle's exit. Under the vacuum effect [11], [18], the secondary fluid from the intercooler will be evaporating, hence, the refrigeration effect at the intercooler is produced. The secondary fluid is then induced to mix with the primary fluid in the ejector before passing through the condenser (From 6 to 7). To complete the EJC cycle, part of condensed liquid from the condenser will be pumped back to the generator (From 7 to 9), while the remainder will be passed through the intercooler (From 8 to 5).

The intercooler works as a condenser for the vapour compression cycle (From 3 to 4). The refrigeration effect produced at the intercooler will be exchanged with the heat rejection from the vapour compression cycle. If the suitable pressure and temperature of the intercooler was set, the compressor work can be decreased and the COP of the system can be increased. Thus, the present of the EJC is to reduce the compressor load of the conventional vapour compression system (From 2 to 3 ). 
This paper focus on a system with a rated cooling capacity of $3.5 \mathrm{~kW}$ (at the evaporator).The parameters concerning the system's operating conditions include boiling temperature $\left(90-120{ }^{\circ} \mathrm{C}\right)$, condensing temperature $\left(30-40^{\circ} \mathrm{C}\right)$, and evaporating temperature $\left(0-10{ }^{\circ} \mathrm{C}\right)$.
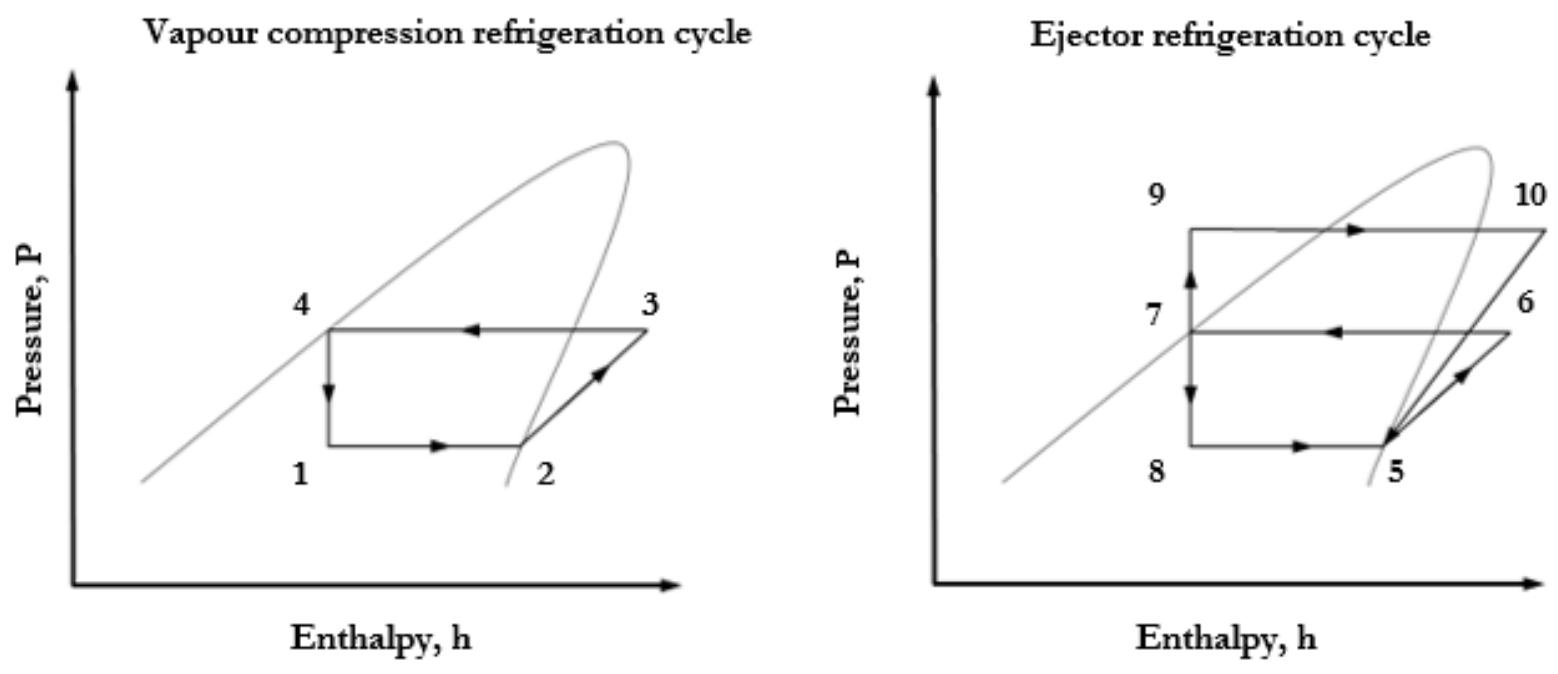

Fig. 2. P-h diagram of a combined ejector-vapour compression refrigeration system.

\section{Research Methodology}

The mathematical analysis of one-dimensional (1-D) and numerical analysis of computational fluid dynamics (CFD) was used in this research in order to find out the performance of the ejector entrainment ratio $(\mathrm{Rm})$, the critical back pressure $(\mathrm{CBP})$ and the coefficient of performance of ejector cycle $\left(\mathrm{COP}_{\mathrm{ej}}\right)$. The results of mathematical modeling would be compared with the experimental results.

Process of calculating the coefficient of performance of a combined ejector-vapour compression refrigeration system use a computer program named Engineering Equation Solver (EES). The calculation procedures are described in Fig. 3. The input parameters of the program are the operating conditions and the size of the ejector. The first set of equations (1-D ejector analysis) results entrainment ratio $(\mathrm{Rm})$ and critical back pressure $\left(\mathrm{P}_{\mathrm{b}}\right)$.

The $\mathrm{Rm}$ will be used as one of the input for thermodynamic analysis. $\mathrm{P}_{\mathrm{b}}$ will be used as a check parameter for the condenser condition. The condenser pressure should be operated below the value of $\mathrm{P}_{\mathrm{b}}$.

The set of thermodynamic equations produces the equipments load including pump power and compressor power as well as determines the COP of the EJC $\left(\mathrm{COP}_{\mathrm{ej}}\right)$.

Temperature of generator $\left(T_{g}\right)$, condenser $\left(T_{c}\right)$, evaporator $\left(T_{e}\right)$, and intercooler $\left(T_{\text {int }}\right)$ were used as input parameters with assumptions of the efficiency of nozzle $\left(\eta_{\mathrm{n}}\right)$, diffuser $\left(\eta_{\mathrm{d}}\right)$, and mixing $\left(\eta_{\mathrm{m}}\right)$ to calculate $\mathrm{M}_{\mathrm{P}, 1}$, $\mathrm{M}_{\mathrm{S}, 1}$, and $\mathrm{P}_{1}$ using Eq. (1), (2), and (9) respectively. The entrainment ratio (Rm) were first assumed in order to calculate the area ratio $\left(\mathrm{A}_{\mathrm{R}}\right)$ until yield the adequate low average error rate of the entrainment ratio compared to the initial value of $\mathrm{Rm}$. For the part of thermodynamics equations, the entrainment ratio and critical back pressure (Rm and CBP).produced from the 1-D equation were used to calculate the COP of mechanical system $\left(\mathrm{COP}_{\mathrm{me}}\right)$, ejector system $\left(\mathrm{COP}_{\mathrm{e}}\right)$, and combined system $\left(\mathrm{COP}_{\text {system }}\right)$ using Eq. (16), (22), and (23) respectively. The results of the mathematical analysis were used as the basic information to design a series of the experiments. Then these results would be compared with the experimental results from the laboratory.

Using 1-D equation, the possible high error rate of Rm and CBP and hence, the calculated COP compared to the experimental results could be obtained because of the assumption of unknown variables in the 1-D equations. In order to improve the analytical results the entrainment ratio ( $\mathrm{Rm}$ ) and the critical back pressure obtained from computational fluid dynamics (CFD) will be also used as input to thermodynamics equations (Fig. 5). Comparisons of the COP results obtained from 1-D equations, CFD simulations and the experiments will be later shown in the results and discussions part. 




Fig. 3. Calculation procedure for the written EES code.

\subsection{Ejector Configuration}

Figure 4 shows a schematic view of the ejector used in the system. From the literatures, the ejector area ratio $\left(D_{t} / D_{n}\right)^{2}$ for the R141b-EJC were often found within the range of 6.25 to 10.33 [19]. The optimum position of ejector was studied by using 1-D model. Also, with the recommendation of the ESDU 86030 [20], Fig. 4 shows the geometry parameters of the ejector specified as follows:

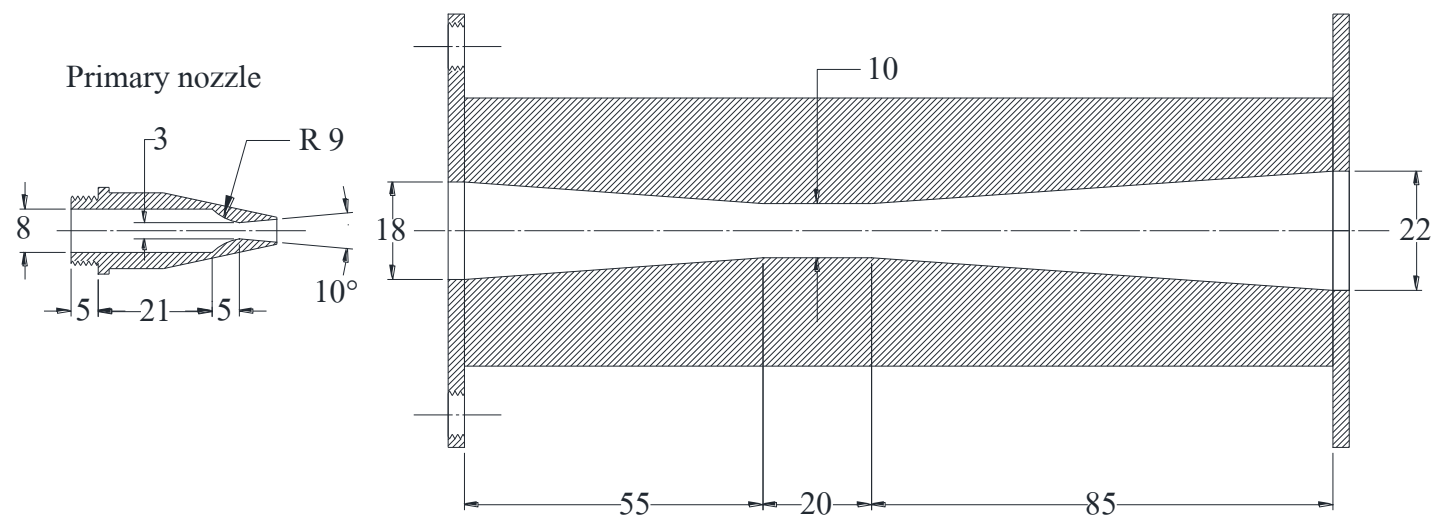

Fig. 4. The interior geometry of an ejector. All dimensions are in $\mathrm{mm}$. 


\subsection{Mathematical Analysis}

Mathematical equation was written in the EES (Engineering Equation Solver). The first set is a set of equations for 1 dimensional analysis of ejector based on Keenan [11] and Aphornratana [18].

\subsubsection{Assumptions}

List of simplified assumptions for ejector analysis is as follows;

1. Friction Losses are accounted by applying loss efficiencies to the primary nozzle and the diffuser.

Nozzle efficiency $\left(\eta_{\mathrm{n}}\right)=0.88$

Diffuser efficiency $\left(\eta_{\mathrm{d}}\right)=0.90$

Mixing efficiency $\left(\eta_{\mathrm{m}}\right)=0.90$

2. Kinetic energies of both the primary fluid and secondary fluid at the ejector inlet and the diffuser outlet are negligible. (Using stagnation properties)

3. The static pressure at the primary nozzle exit plane where the two fluid streams first met is assumed to be uniform.

4. The two streams completely mix before a normal shock wave occurs at the end of the mixing chamber.

\subsubsection{Ejector analysis}

The analysis of 1D theory of Keenan and Aphornratana was based on the ideal gas assumption combined with the principles of mass, momentum, and energy conservation. For a study flow process, the equations are given as follows:

The Mach number of the primary fluid at the nozzle exit plane, therefore, can be calculated using:

$$
M_{2}^{\prime}=\sqrt{\frac{2 \eta_{n}}{k-1}\left[\left(\frac{P_{P_{0}}}{P_{2}}\right)^{\frac{k-1}{k}}-1\right]}
$$

The Mach number of the secondary fluid at the nozzle exit plane, therefore, can be calculated using:

$$
\mathrm{M}_{2}=\sqrt{\frac{2}{\mathrm{k}-1}\left[\left(\frac{\mathrm{P}_{\mathrm{S}_{0}}}{\mathrm{P}_{2}}\right)^{\frac{\mathrm{k}-1}{\mathrm{k}}}-1\right]}
$$

The association among $\mathrm{M}$ and $\mathrm{M}^{*}$ can be presented as:

$$
M^{*}=\sqrt{\frac{(k+1) \times\left(\frac{M^{2}}{2}\right)}{1+(k-1) \times\left(\frac{M^{2}}{2}\right)}}
$$

Mach number is able to calculate using the equations of conservation of mass, momentum and energy: 


$$
\mathrm{M}_{5}^{*}=\eta_{\mathrm{m}}\left[\frac{\mathrm{M}_{2}^{*}+\left(\mathrm{M}_{2}^{*} \times \mathrm{Rm} \times \sqrt{\frac{\mathrm{T}_{\mathrm{S}}}{\mathrm{T}_{\mathrm{P}}}}\right)}{\sqrt{(1+\mathrm{Rm}) \times\left(1+\mathrm{Rm} \times \sqrt{\frac{\mathrm{T}_{\mathrm{S}}}{\mathrm{T}_{\mathrm{P}}}}\right)}}\right]
$$

Suppose that the normal shock wave appear in the midst of state 5 and 6 , the mixed fluid that occur instantly after the normal shock wave can be written in terms of Mach number as:

$$
M_{6}=\sqrt{\frac{M_{5}^{2}+\frac{2}{(k+1)}}{\left(\frac{2 \times k}{k-1} \times M_{5}^{2}\right)-1}}
$$

The pressure ratio across the normal shock wave is calculated from:

$$
\frac{\mathrm{P}_{6}}{\mathrm{P}_{5}}=\frac{1+\mathrm{k} \times \mathrm{M}_{5}^{2}}{1+\mathrm{k} \times \mathrm{M}_{6}^{2}}
$$

If assumed that the flow speed is brought to stagnation state at the end of the diffuser and a loss coefficient of the diffuser $\left(\eta_{\mathrm{d}}\right)$ is applied, the pressure ratio across the subsonic diffuser can be written as:

$$
\frac{\mathrm{P}_{\mathrm{b}}}{\mathrm{P}_{6}}=\left[\left(\frac{\eta_{\mathrm{d}}(\mathrm{k}-1)}{2} \cdot \mathrm{M}_{6}^{2}\right)+1\right]^{\left(\frac{\mathrm{k}}{\mathrm{k}-1}\right)}
$$

The mass flow rate of the primary fluid $\left(\dot{\mathrm{m}}_{\mathrm{P}}\right)$ is calculated using theory of compressible gas flow through convergent-divergent nozzle which is the critical mass flow rate or maximum mass flow rate for a given throat diameter of the nozzle.

$$
\dot{\mathrm{m}}_{\mathrm{P}}=\frac{\mathrm{A}_{1} \mathrm{P}_{\mathrm{P}_{0}}}{\sqrt{\frac{\mathrm{R} \cdot \mathrm{T}_{\mathrm{P}_{0}}}{\mathrm{k}}\left(\frac{\mathrm{k}+1}{2}\right)^{\frac{\mathrm{k}+1}{\mathrm{k}-1}}}}
$$

Thus, the cross section area at the throat of the primary nozzle can be written as:

$$
\mathrm{A}_{1}=\frac{\dot{\mathrm{m}}_{\mathrm{P}}}{\mathrm{P}_{\mathrm{P}_{0}}} \sqrt{\frac{\mathrm{R} \cdot \mathrm{T}_{\mathrm{P}_{0}}}{\mathrm{k}}\left(\frac{\mathrm{k}+1}{2}\right)^{\frac{\mathrm{k}+1}{\mathrm{k}-1}}}
$$

Applying continuity equation of an ideal gas between state 1 and $2^{\prime}$, the cross sectional area at the primary nozzle exit can be calculated using the following equation: 


$$
\frac{A_{2}^{\prime}}{A_{1}}=\frac{\left(\frac{2}{k+1}\right)^{\frac{1}{k-1}\left(\frac{P_{P_{0}}}{P_{2}}\right)^{\frac{1}{k}}}}{\sqrt{\frac{k+1}{k-1} \cdot\left(1-\left(\frac{P_{2}}{P_{P_{0}}}\right)^{\frac{k-1}{k}}\right)}}
$$

On the other hand, the annular cross sectional area of the secondary fluid at the primary nozzle exit plane (inlet of mixing chamber) is determined from:

$$
\frac{A_{2}{ }^{\prime}}{A_{1}}=\frac{R m \cdot \sqrt{\frac{T_{S_{0}}}{T_{P_{0}}} \cdot\left(\frac{2}{k+1}\right)^{\frac{1}{k-1}} \cdot\left(\frac{P_{P_{0}}}{P_{S_{0}}}\right) \cdot\left(\frac{P_{S_{0}}}{P_{2}}\right)^{\frac{1}{k}}}}{\sqrt{\frac{k+1}{k-1} \cdot\left(1-\left(\frac{P_{2}}{P_{P_{0}}}\right)^{\frac{k-1}{k}}\right)}}
$$

If a zero thickness of the primary nozzle exit's wall is assumed, the mixing chamber inlet diameter can be expressed as:

$$
\mathrm{A}_{2}=\mathrm{A}_{2}^{\prime}+\mathrm{A}_{2}^{\prime \prime}
$$

The area ratio (AR) between the cross section areas of constant area's throat to the cross section area of the primary nozzle's throat can finally be obtained as follows:

\subsection{Numerical Analysis}

$$
\frac{A_{6}}{A_{1}}=\frac{\sqrt{(1+R m)\left[1+R m\left(\frac{T_{S}}{T_{P}}\right)\right] \cdot\left(\frac{2}{k+1}\right)^{\frac{1}{k+1}} \cdot\left(\frac{P_{P_{0}}}{P_{b}}\right) \cdot\left(\frac{P_{b}}{P_{6}}\right)^{\frac{1}{k}}}}{\sqrt{\frac{k+1}{k-1} \cdot\left(1-\left(\frac{P_{6}}{P_{b}}\right)^{\frac{k-1}{k}}\right)}}
$$

Numerical analysis via computational fluid dynamics (CFD) technique was used in this research in order to find out the performance of the ejector entrainment ratio (Rm), the critical back pressure (CBP). The following assumptions were taken to account:

1. The two-dimensional geometry of the model is Axisymmetric.

2. The "realizable k- $\mathrm{\varepsilon}$ model" was selected to govern the turbulence characteristic [21].

3. Model ejector divided by the Quad Grid was 101,900 has been revised and tested in different resolutions to ensure the accuracy of the simulation flow. Found that the error of the entrainment ratio $(\mathrm{Rm})$ is less than $1 \%$

Figure 5 displays the calculation procedure for numerical analysis of computational fluid dynamics (CFD). The input parameters including temperature of generator $\left(T_{g}\right)$, condenser $\left(T_{c}\right)$, evaporator $\left(T_{e}\right)$, and intercooler $\left(T_{\text {int }}\right)$ were used to find the primary and secondary flows and subsequently yielded the value of $\mathrm{Rm}$ and $\mathrm{P}_{\mathrm{b}}$ from CFD. Equations (14)-(17) were used to find the energy conservations of evaporator $\left(\dot{\mathrm{Q}}_{\mathrm{e}}\right)$, vapor generator $\left(\dot{\mathrm{Q}}_{\mathrm{g}}\right)$, and condenser $\left(\dot{\mathrm{Q}}_{\mathrm{c}}\right)$, in order to yield the coefficient of performance of the ejector $\left(\mathrm{COP}_{\mathrm{e}}\right)$ using Eq. (23). 


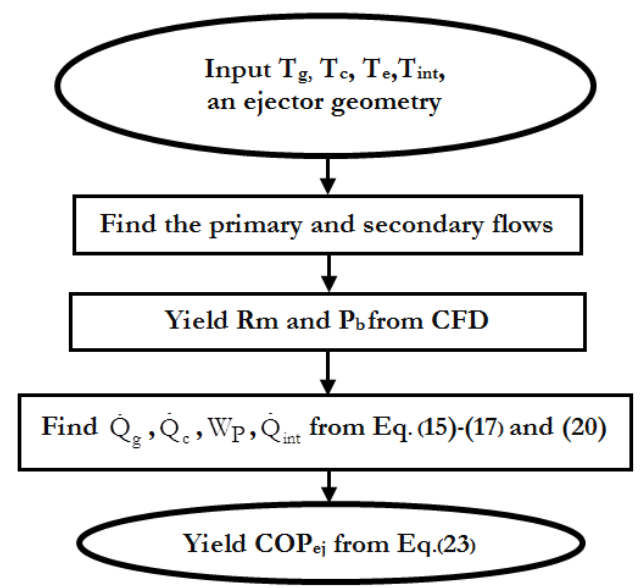

Fig. 5. Calculation procedure for numerical analysis of computational fluid dynamics (CFD).

\subsection{Experimental Setup}

Figures 6 and 7 show the schematic diagram and photographs of the experimental setup, respectively. The vapour compression refrigeration system (VCS) consists of an inverter compressor, a heat exchanger, an expansion valve, an evaporator and measuring devices. The inverter compressor rated output power is 2.2 $\mathrm{kW}(50 \mathrm{~Hz})$. Speed of the compressor is about the speed of a car. So while idling the car's engine, compressor rotates around $600-800 \mathrm{rpm}$ and a top speed of approximately 5,000 rpm. In this experiment, the simulation speed compressor was used a $3 \mathrm{hp}$ motor and controlled the speed by inverter motor. The accuracy of the output frequency is $\pm 0.1 \mathrm{~Hz}$.

The plate heat exchanger was designed with the pressure of $30 \mathrm{bar}$ and the total heat transfer area of $0.56 \mathrm{~m}^{2}$. Plate heat exchanger, which made of Stainless Steel 316 and Copper with Nickle as a welder to prevent leak (Brazed), was used because the property of high corrosion resistance to various types of fluid. In addition, the heat exchanger is smaller and lighter than the shell and tube heat exchangers. With this feature, the plate heat exchangers are easy to install or maintenance.

Evaporator is a device that absorbs heat load in the car's passenger space. Evaporator consists of copper tubes and aluminum fins to increase surface area for heat transfer. This experiment simulates the load of the system by using a controlled temperature-water tank to control the temperature within range $\pm 2{ }^{\circ} \mathrm{C}$, as shown in Fig. 6 .

The EJC consists of a generator, an air-cooled condenser, a liquid receiver, a heat exchanger, an ejector, a pump, and measuring devices.

The generator is used for generate steam of the refrigerant. The pipe is made of stainless steel of 6 inches in diameter and $6 \mathrm{~mm}$ thick, $130 \mathrm{~cm}$ long with 3 plates of Baffle welded to the pipe to prevent mixing of fluid and vapor. A glass tube at the side of the tank is equipped for monitoring the level of refrigerant. The refrigerant in the boiler is heated by electric heater $9 \mathrm{~kW}$ at the bottom of the tank. The heater is controlled by a digital thermostat within $\pm 0.5 \%$ of full scale.

The condenser is a copper tube attached with aluminum fin. The maximum cooling load is $14 \mathrm{~kW}$.

The following instruments were used to measure all necessary parameters including; pressure gauges with error of $\pm 1.6 \%$ of full scale. Thermocouples type $\mathrm{K}$ with error of $\pm 1.5^{\circ} \mathrm{C}$. Two Rota meters were used to measure the primary and entrained flows of the ejector with error of $\pm 2 \%$ of full scale.

The operating conditions of the VCS and EJC considered for the evaluation of the performance of the ECC are given in Table 2.

Calculation procedure for the written EES code from the experiment is presented in Fig. 8. The experiment was setup to control the operation parameters for finding the primary and secondary flows and yielding the value of $\mathrm{Rm}$ and $\mathrm{Pb}$ consequently. As well as the CFD approach in Fig. 5, Eq. (14)-(17) were used to find the energy conservations of evaporator $\left(\dot{Q}_{e}\right)$, vapor generator $\left(\dot{Q}_{g}\right)$ and condenser $\left(\dot{Q}_{c}\right)$ and accordingly yielded the coefficient of performance of the ejector $\left(\mathrm{COP}_{\mathrm{e}}\right)$ and the mechanical system $\left(\mathrm{COP}_{\mathrm{me}}\right)$ using Eq. (23) and (19) respectively. 


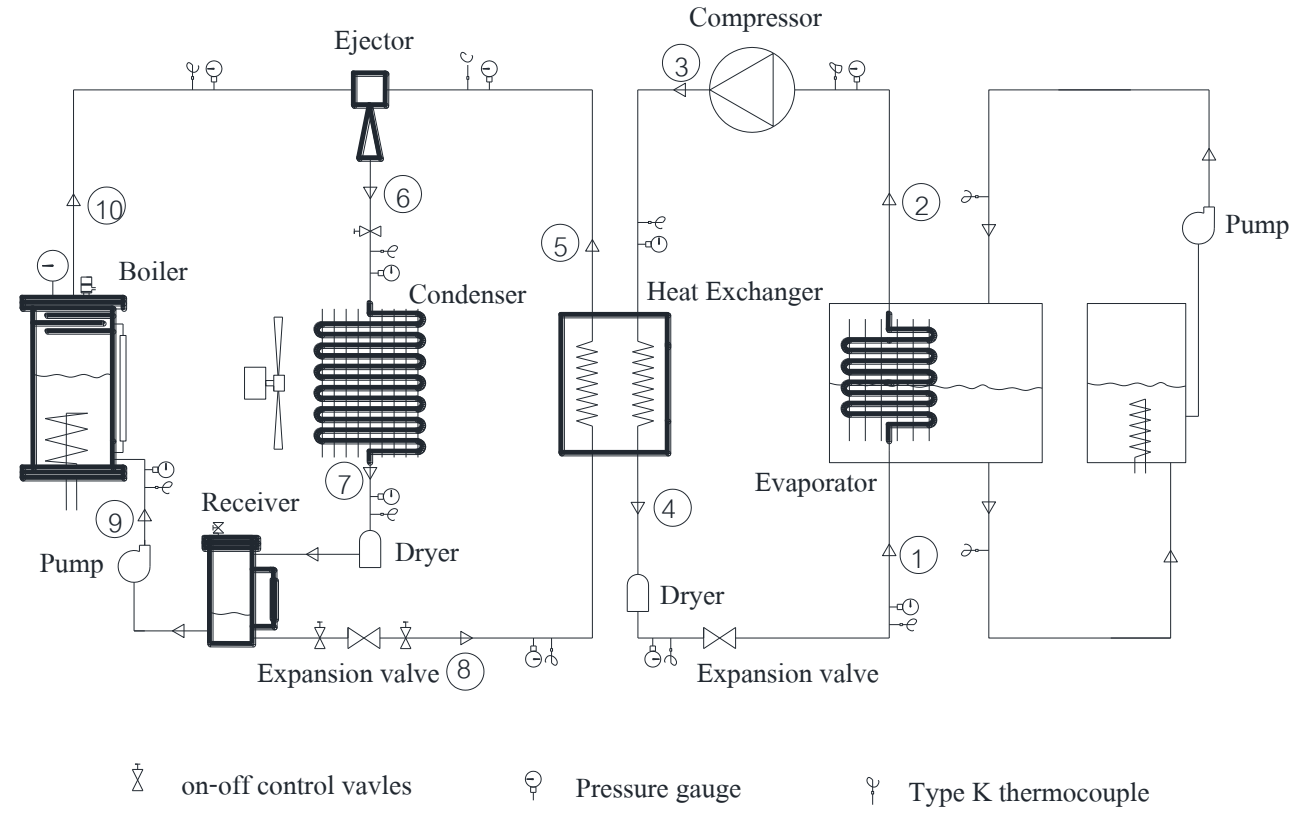

Fig. 6. Schematic drawing of the experimental.



Fig. 7. Photograph of the experimental rig. 


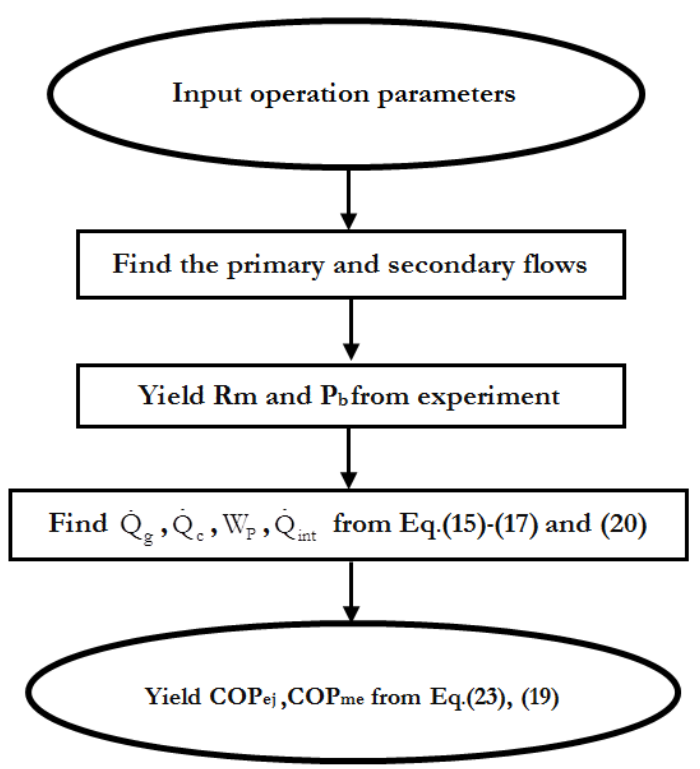

Fig. 8. Calculation procedure for the written EES code from the experiment.

Table 2. Operation parameters for the combined ejector-vapor compression cycle for various COP.

\begin{tabular}{ll}
\hline Operation conditions of the EJC. & \\
\hline Refrigerant & $\mathrm{R} 141 \mathrm{~b}$ \\
Generating temperature of EJC $\left(\mathrm{T}_{\mathrm{g}}\right),{ }^{\circ} \mathrm{C}$ & $90-120$ \\
Intercooler temperature of EJC $\left(\mathrm{T}_{\text {int }}\right),{ }^{\circ} \mathrm{C}$ & $15-25$ \\
Condensing temperature of EJC $\left(\mathrm{T}_{\mathrm{c}}\right),{ }^{\circ} \mathrm{C}$ & $35-40$ \\
\hline Operation conditions of the VCC. & $\mathrm{R} 134 \mathrm{a}$ \\
\hline Refrigerant & $0-10$ \\
Evaporating temperature of VCC $\left(\mathrm{T}_{\mathrm{e}}\right),{ }^{\circ} \mathrm{C}$ & $20-50$ \\
Compressor inverter control determines the range of $(\mathrm{Hz})$ & $2-3.5$ \\
Cooling capacity, $\mathrm{kW}$ & $0.5-1.5$ \\
Compressor input, $\mathrm{kW}$ & $35-40$ \\
Condensing temperature of EJC $\left(\mathrm{T}_{\mathrm{c}}\right),{ }^{\circ} \mathrm{C}$ & \\
\hline
\end{tabular}

\subsection{Thermodynamic Analysis}

For thermodynamic analysis of the combined system, the following assumptions were taken to account:

1. The flow through the throttle valve is isenthalpic.

2. The process at compressor is isentropic and work in put at pump is neglected.

3. The condenser outlet state is saturated liquid and the evaporator outlet state is saturated vapour.

4. Amount of power consumed by fans at condenser and evaporator are neglected.

5. The systems are simulated under steady state conditions.

Using the information in Fig. 3 and the mass and energy conservations, the cycle's performance is analyzed theoretically.

In the evaporator, vapor generator and condenser, the energy conservations are calculated from Eq. (14), (15) and (16):

$$
\begin{aligned}
& \dot{\mathrm{Q}}_{\mathrm{e}}=\dot{\mathrm{m}}_{1}\left(\mathrm{~h}_{2}-\mathrm{h}_{1}\right) \\
& \dot{\mathrm{Q}}_{\mathrm{g}}=\dot{\mathrm{m}}_{9}\left(\mathrm{~h}_{10}-\mathrm{h}_{9}\right)
\end{aligned}
$$




$$
\dot{\mathrm{Q}}_{\mathrm{c}}=\dot{\mathrm{m}}_{6}\left(\mathrm{~h}_{6}-\mathrm{h}_{7}\right)
$$

The pump work and the compressor work are calculated from Eq. (17) and (18):

$$
\begin{gathered}
\mathrm{W}_{\mathrm{P}}=\dot{\mathrm{m}}_{9}\left(\mathrm{~h}_{9}-\mathrm{h}_{7}\right) \\
\mathrm{W}_{\text {com }}=\dot{\mathrm{m}}_{1}\left(\mathrm{~h}_{3}-\mathrm{h}_{2}\right)
\end{gathered}
$$

Coefficient of performance mechanical system:

$$
\mathrm{COP}_{\mathrm{me}}=\frac{\dot{\mathrm{Q}}_{\mathrm{e}}}{\mathrm{W}_{\mathrm{com}}}
$$

Heat flow rate at the intercooler can be calculated using the following equations.

$$
\begin{gathered}
\dot{\mathrm{Q}}_{\mathrm{int}}=\dot{\mathrm{m}}_{5}\left(\mathrm{~h}_{5}-\mathrm{h}_{8}\right)=\varepsilon \dot{\mathrm{m}}_{3}\left(\mathrm{~h}_{3}-\mathrm{h}_{4}\right) \\
\dot{\mathrm{Q}}_{\mathrm{int}}=\varepsilon\left(\dot{\mathrm{Q}}_{\mathrm{e}}+\mathrm{W}_{\text {com }}\right)
\end{gathered}
$$

The coefficient of performance (COP) of the cycle can be determined by

$$
\mathrm{COP}_{\mathrm{ej}}=\frac{\dot{\mathrm{Q}}_{\text {int }}}{\mathrm{W}_{\mathrm{P}}+\dot{\mathrm{Q}}_{\mathrm{g}}}
$$

Equation (20) can be expressed as,

$$
\mathrm{COP}_{\mathrm{ej}}=\mathrm{Rm} \frac{\mathrm{h}_{5}-\mathrm{h}_{8}}{\mathrm{~h}_{10}-\mathrm{h}_{7}}
$$

The coefficient of performance ( $\left.\mathrm{COP}_{\text {system }}\right)$ of the combined cycle can be determined by

$$
\mathrm{COP}_{\text {system }}=\frac{\dot{\mathrm{Q}}_{\mathrm{e}}}{\dot{\mathrm{Q}}_{\mathrm{g}}+\mathrm{W}_{\mathrm{com}}+\mathrm{W}_{\mathrm{P}}}
$$

In order to verify the accuracy of experiments, the calculated relative combined uncertainty is mandatory. As stated in Section 3.4 Experimental Setup, temperature, pressure, and refrigerant mass flow rate were measured with instruments. The computed parameters including $R m, \dot{Q}_{e}, W_{c o m}, C O P_{e j}$, and $\mathrm{COP}_{\mathrm{me}}$ were examined regarding uncertainty. A set of independent variables $\mathrm{X}_{\mathrm{i}}$ could be used to derive the parameter $f$, as displayed in Eq. (25).

$$
f=f\left(\mathrm{X}_{1}+\mathrm{X}_{2}+\ldots\right)
$$

Using the root sum square method, Eq. (26) describes the uncertainty $\delta f$ which is combined uncertainty of individual terms.

$$
\delta f=\sqrt{\left(\frac{\partial f}{\partial \mathrm{X}_{1}} \delta \mathrm{X}_{1}\right)^{2}+\left(\frac{\partial f}{\partial \mathrm{X}_{2}} \delta \mathrm{X}_{2}\right)^{2}+\left(\frac{\partial f}{\partial \mathrm{X}_{3}} \delta \mathrm{X}_{3}\right)^{2}+\ldots}
$$


Hence, the calculated relative combined uncertainty of $\mathrm{Rm}, \dot{\mathrm{Q}}_{\mathrm{e}}$, , $\mathrm{W}_{\mathrm{com}}, \mathrm{COP}_{\mathrm{e}}$, and $\mathrm{COP}_{\mathrm{me}}$ were $0.3 \%$, $5.6 \%, 4.3 \%, 3.8 \%$, and $7.1 \%$, respectively.

\section{Results and Discussion}

The input data in Table 2 were used in the study. The result in Fig. 9 illustrates how the entrainment ratio $(\mathrm{Rm})$ varies with secondary fluid temperature of the ejector. This result obtained at fixed conditions of condenser temperature and evaporator temperature of $35{ }^{\circ} \mathrm{C}$ and $5{ }^{\circ} \mathrm{C}$, respectively. However, the generator temperature was varied between $110^{\circ} \mathrm{C}$ and $120^{\circ} \mathrm{C}$.

It is obvious that the combined ejector-vapour compression refrigeration system with lower generator temperature produced higher entrainment ratio. Increasing in the intercooler temperature from 18 to $25^{\circ} \mathrm{C}$ provide the increment of the entrainment ratio.

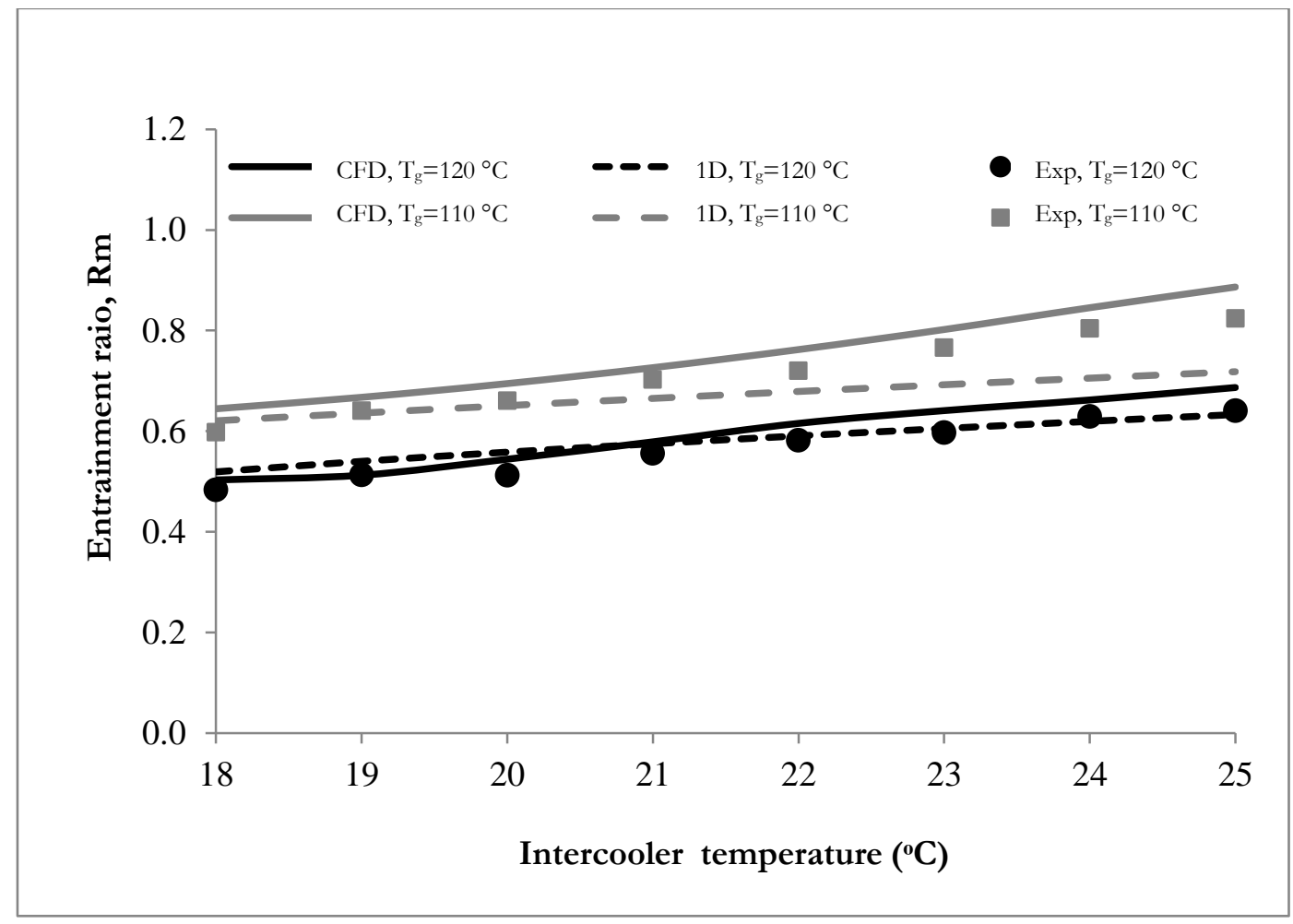

Fig. 9. Variation of entrainment ratio $(R m)$ with intercooler temperature $\left(T_{\text {int }}\right),\left(T_{c}=35^{\circ} \mathrm{C}\right)$. 


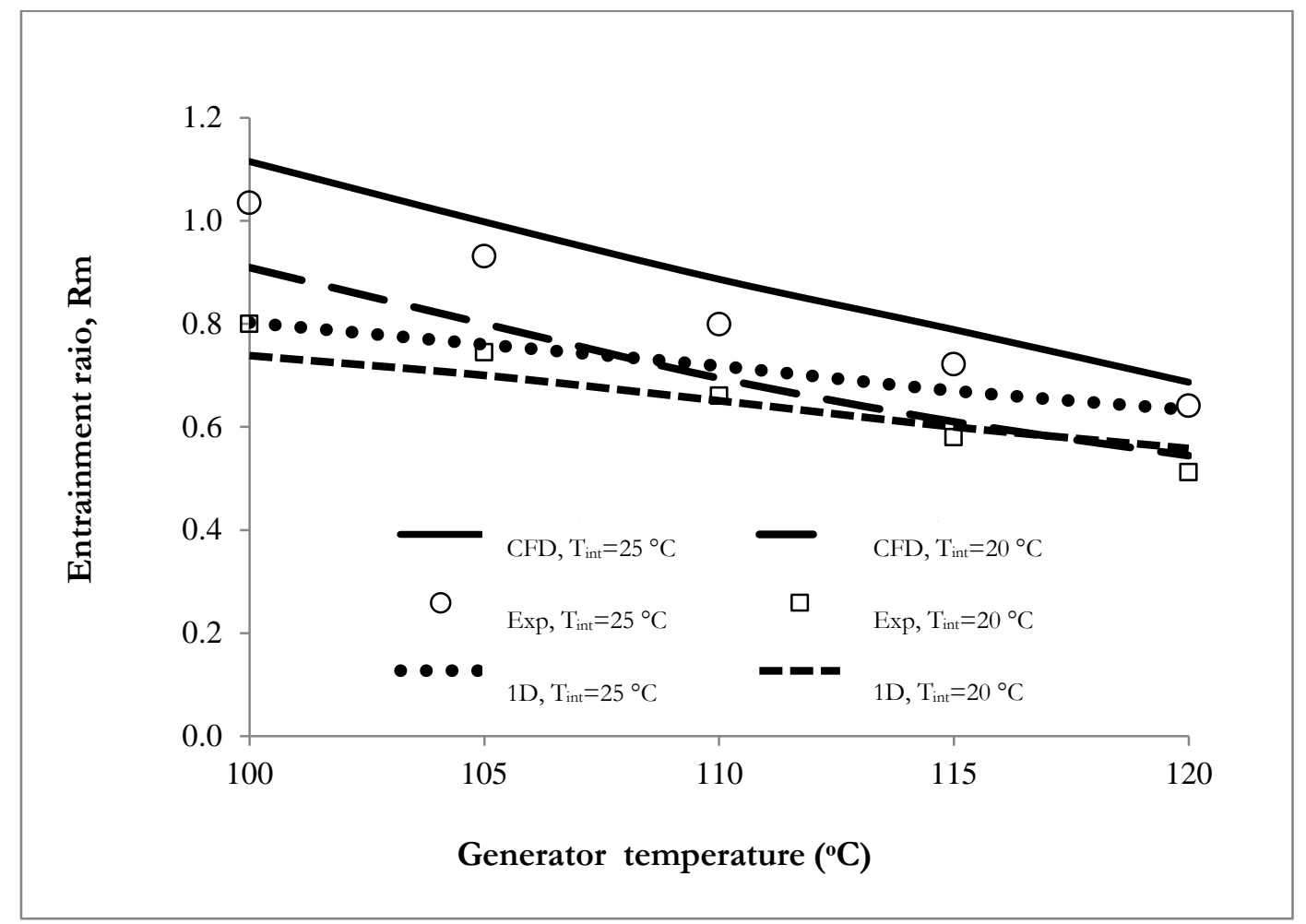

Fig. 10. Variation of entrainment ratio $(R m)$ with generator temperature $\left(T_{g}\right),\left(T_{c}=35^{\circ} \mathrm{C}\right)$.

The variation of entrainment ratio $(\mathrm{Rm})$ in the combined cycle with intercooler temperature is shown in Fig. 9. For the generator temperature of $110{ }^{\circ} \mathrm{C}$ and $120{ }^{\circ} \mathrm{C}$ and a fix condenser temperature of $35^{\circ} \mathrm{C}$, the $\mathrm{Rm}$ was found to increase with the intercooling temperature. It also found that increasing the generator temperature decreases the Rm. These results are similar to those presented by Wang [21]. Refer to Fig. 9, the intercooler temperature increases related to the entrainment ratio. This is proven since the pressure in the intercooler is higher than the pressure at the primary nozzle exit. In the intercooler, higher temperature, higher pressure. Consequently, the higher difference of pressure between the evaporator and the primary nozzle exit cause the entrained mass flow rate to be increased. Although a rise in intercooler pressure causes an increase in vapour flow rate by entering of the intercooler to the ejector, the primary flow rate remains unchanged. The results obtained from CFD analysis provide better results than the onedimensional analysis(1D) with average error of 5.6\% compared to experiment(Exp)value.

Figure 10 illustrates the variation of entrainment ratio $(\mathrm{Rm})$ with generator temperature. It can be seen that $\mathrm{Rm}$ decreases with the increase in generator temperature at a particular condenser temperature of $35^{\circ} \mathrm{C}$ and intercooler temperatures of $20^{\circ} \mathrm{C}$ and $25^{\circ} \mathrm{C}$. From Fig. 10, a maximum $\mathrm{Rm}$ of 1.10 was found for $\mathrm{T}_{\mathrm{g}}=100{ }^{\circ} \mathrm{C}, \mathrm{T}_{\mathrm{c}}=35^{\circ} \mathrm{C}, \mathrm{T}_{\text {int }}=25^{\circ} \mathrm{C}$. CFD analysis errors lower $10 \%$ and one-dimensional predictions of up to $15.5 \%$. An optimum entrainment ratio occurs when the operating conditions reach the critical mode. In such mode, the secondary flow rate is constant even though the primary flow rate increases, the entrainment ratio decreases consequently. Compare to performance of the ejector cycle with generating pressure range of 10-25 bar presented in [21], the ejector entrainment ratio line has decrease when generator decrease. More entrainment of the fluid from the evaporator due to higher momentum exchange describes the increase of the entrainment ratio with the increase in the motive temperature. Due to the shock wave, the energy loss appears and the difference of the pressure between the motive and secondary fluid decreases, the entrainment ratio decreases continuously as similar shape as displays in Fig. 10. 


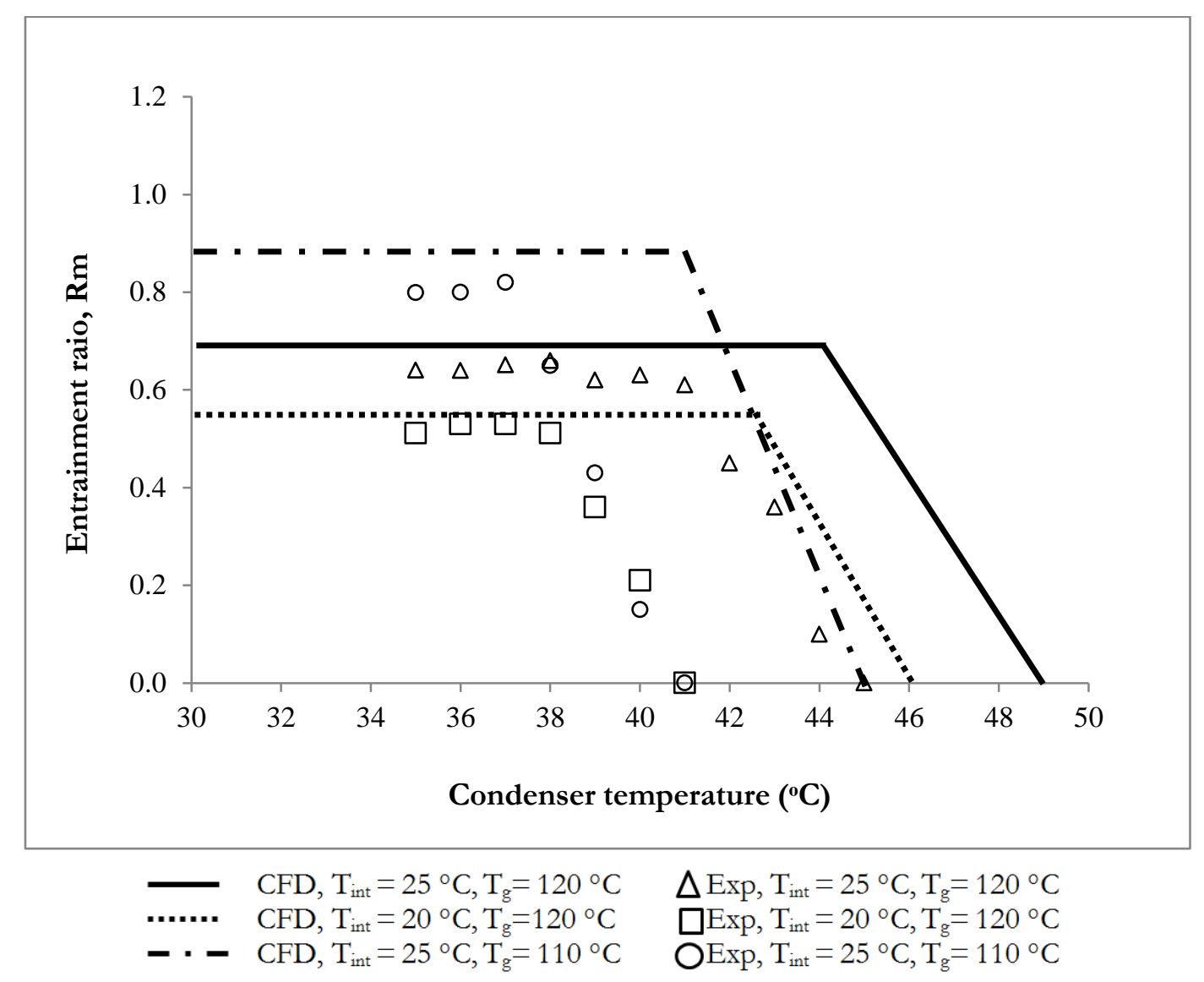

Fig. 11. Variation of entrainment ratio $(\mathrm{Rm})$ with condenser temperature $\left(\mathrm{T}_{\mathrm{c}}\right)$.

Figure 11 shows the experimental results comparing with corresponding computational fluid dynamics (CFD). When the generating temperature are fixed at 110 and $120^{\circ} \mathrm{C}$ and the intercooler temperature at 20 and $25^{\circ} \mathrm{C}$. The results indicate effect of critical back pressure. When the ejector back pressure is lower than the critical back pressure, the entrainment ratio keeps constant. After the critical back pressure, the entrainment ratio decreases with an increase in the condenser temperature. The results found in the present study are similar to Wang [21] study. Although on-design operating regime of the ejector is extended by higher motive generator temperature but the maximum mass entrainment ratio is lowered. For hot climate area, this ejector operation's feature is very significant because higher condensation temperatures could be anticipated easily. 


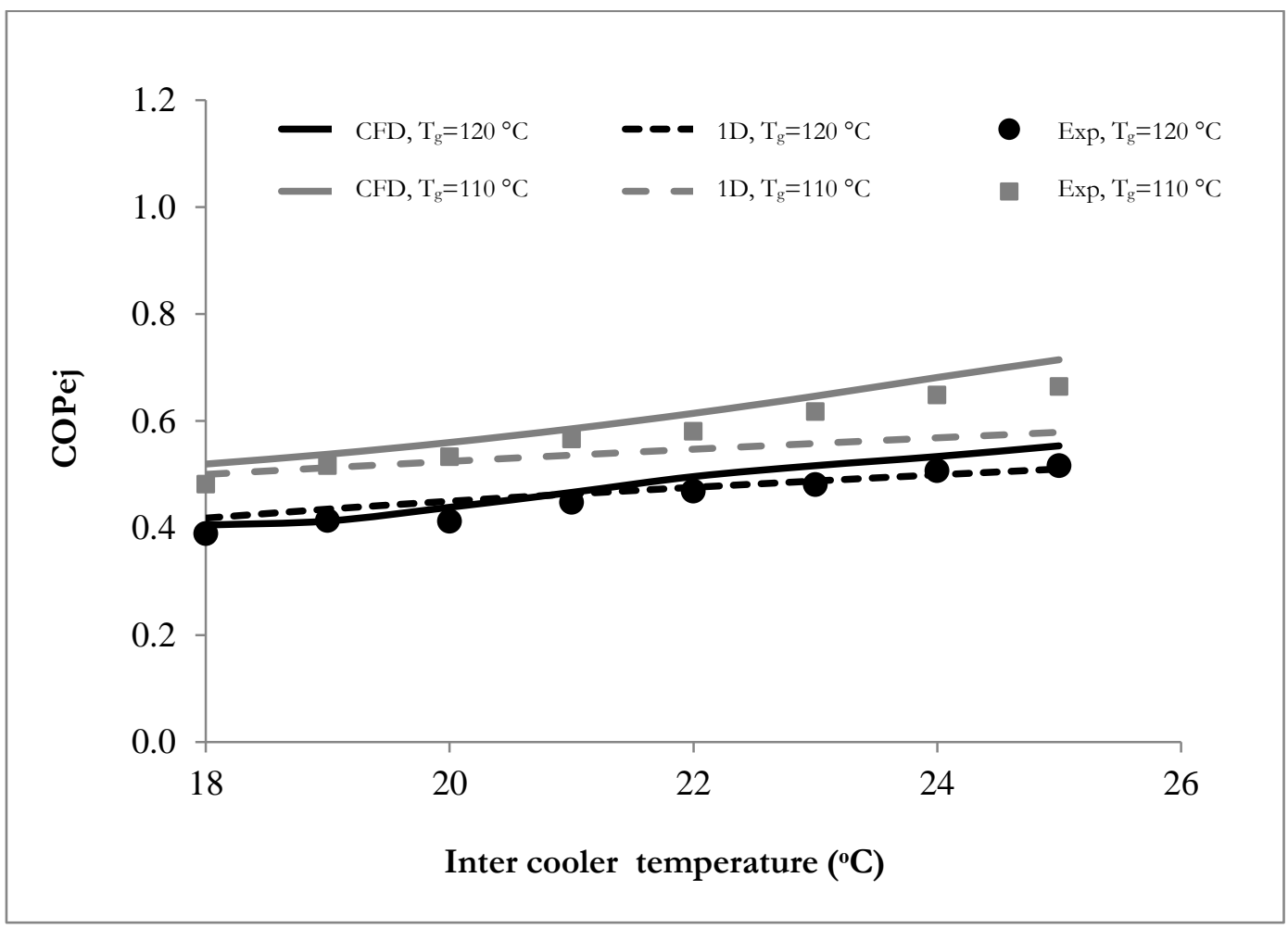

Fig. 12. Variation of $\mathrm{COP}_{\mathrm{ej}}$ with intercooler temperature $\left(\mathrm{T}_{\mathrm{c}}=35^{\circ} \mathrm{C}\right)$.

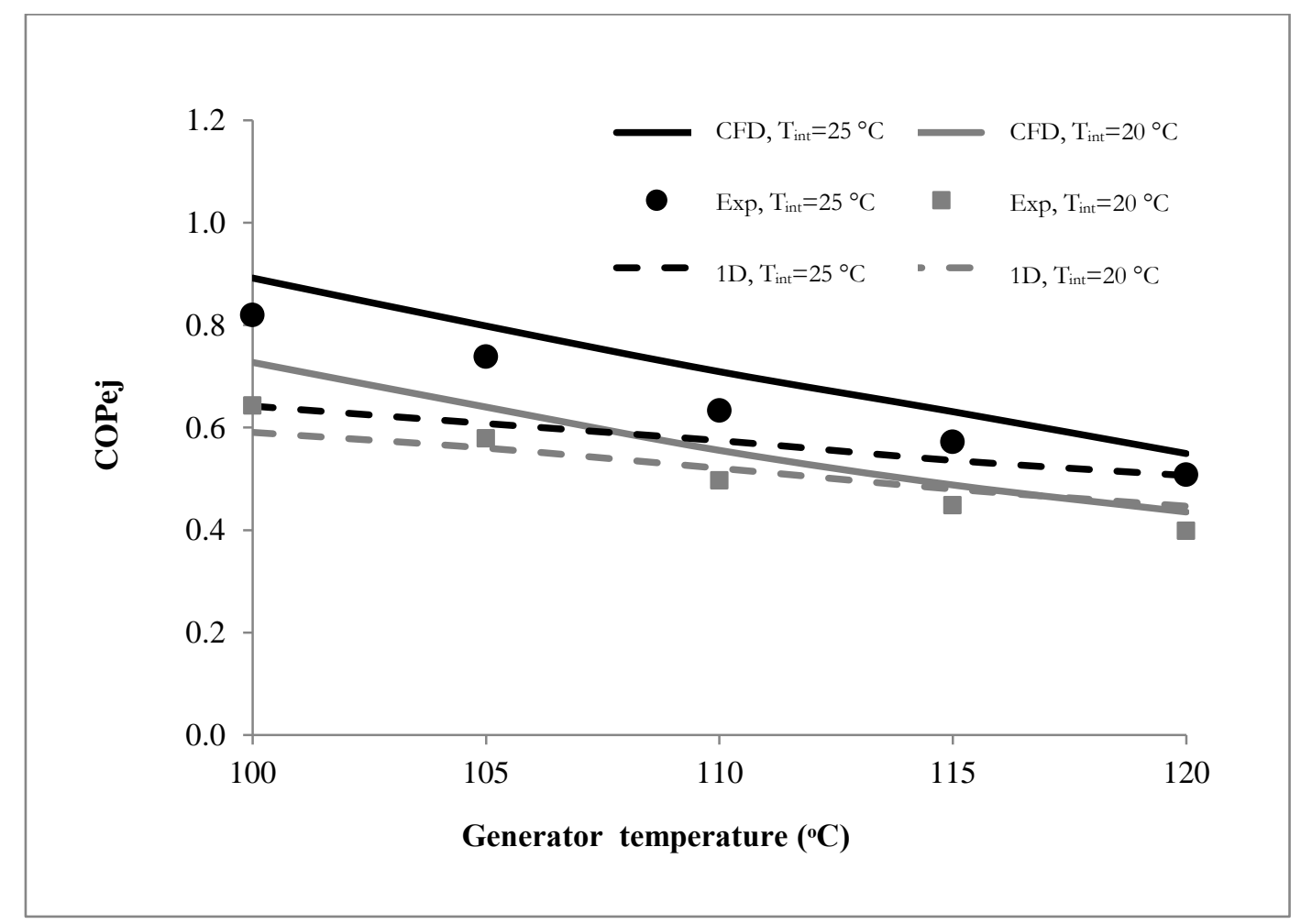

Fig. 13. Variation of $\mathrm{COP}_{\mathrm{ej}}$ with generator temperature $\left(\mathrm{T}_{\mathrm{c}}=35^{\circ} \mathrm{C}\right)$.

The experimental effects on the coefficient of performance $\left(\mathrm{COP}_{\mathrm{ej}}\right)$ are shown in Fig. 13 of the generator temperature. The results in Fig. 13 are obtained for a condenser temperature of $35{ }^{\circ} \mathrm{C}$ and intercooler temperature of 20 and $25^{\circ} \mathrm{C}$. Found that increasing of the temperature of the generator vary 
inversely to the COP of the ejector as display in Fig. 9. The secondary fluid temperature increases from $20{ }^{\circ} \mathrm{C}$ to $25{ }^{\circ} \mathrm{C}$, the COP of the ejector increased approximately $30 \%$.

Figure 12 presents the experimental results for the COP of the ejector system $\left(\mathrm{COP}_{\mathrm{ej}}\right)$. The ejector refrigeration system operates with a generator temperature of 110 and $120^{\circ} \mathrm{C}$ and a condenser temperature of $35{ }^{\circ} \mathrm{C}$ for refrigeration capacity of $3.5 \mathrm{~kW}$. The results showed that the primary fluid temperature increases from $110^{\circ} \mathrm{C}$ to $120^{\circ} \mathrm{C}$, the COP of the ejector decreased approximately $20 \%$.

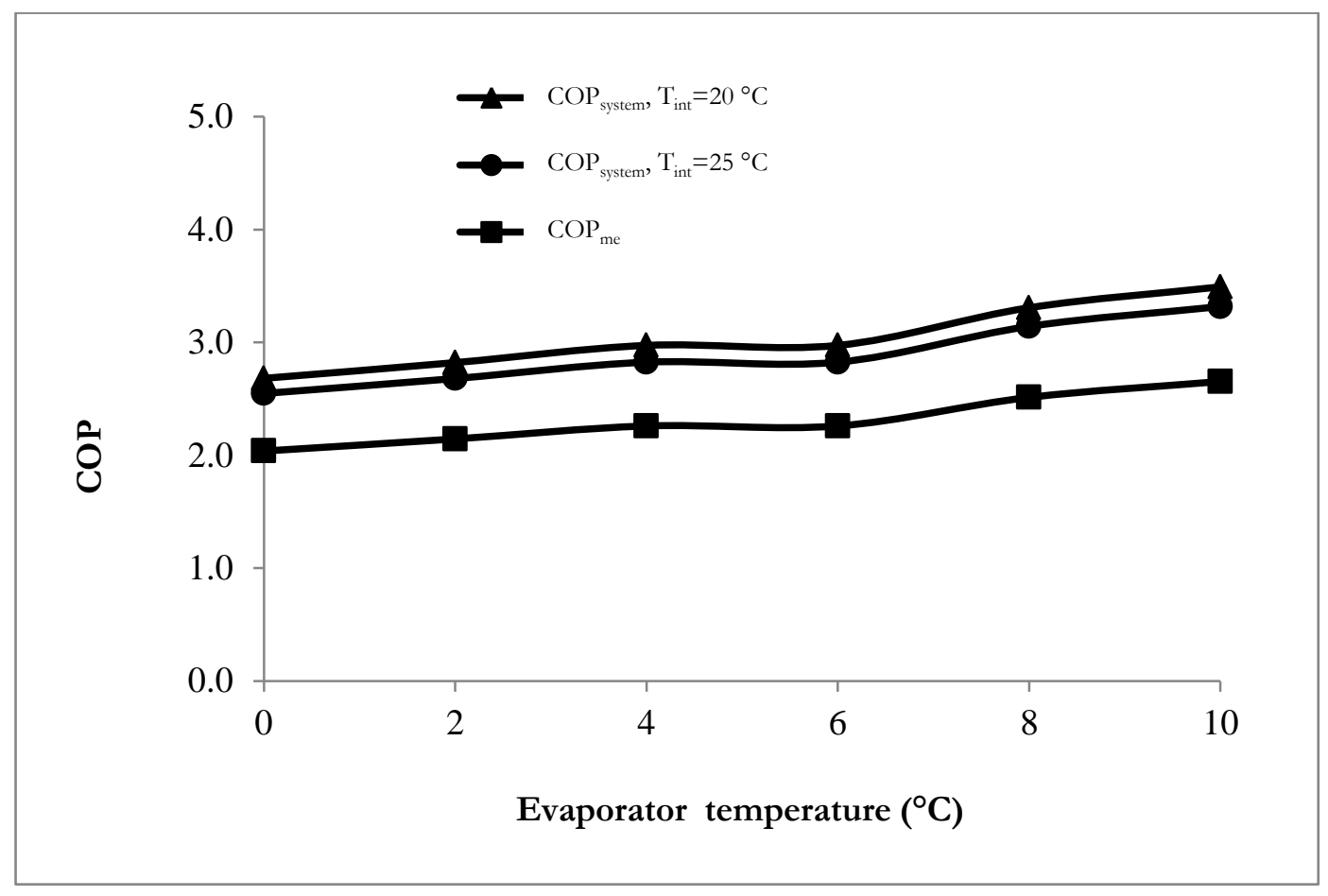

Fig. 14. Variation of COP with evaporating temperature.

Figure 14 displays the COP of the combined system ( $\left.\mathrm{COP}_{\text {system }}\right)$ compares with the $\mathrm{COP}$ of the vapor compression system $\left(\mathrm{COP}_{\mathrm{me}}\right)$ under determined conditions. From, Eq. (24), the heat supplied at the generator $\left(\dot{\mathrm{Q}}_{\mathrm{e}}\right)$ can be obtained from the waste heat i.e., the car's exhaust gas. In order to complete with the vapour compression system this heat will be neglected. The ejector refrigeration system operated with a generator temperature of $120^{\circ} \mathrm{C}$, a condenser temperature of $35^{\circ} \mathrm{C}$, and refrigeration capacity of 3.5 $\mathrm{kW}$. The combined system is able to improve the COP around 10-20\% from the only vapor compression system. The COP value obtained from the ratio of the refrigeration capacity to the compressor power. Found that, at the same refrigeration capacity, a temperature increase of the cooling coil cause the COP to be increased as well because the compressor power was dropped (Fig. 15). Reducing the temperature of the heating coil or the heat exchanger will also raises the COP since the power driven the compressor was decreased[22].

Figure 15 displays the variation of the compressor power for the combined system $\left(\mathrm{W}_{\text {system }}\right)$ compares with the conventional vapour compression system $\left(\mathrm{W}_{\mathrm{me}}\right)$. On average, $20 \%$ reduction of power consumption by applying the combined system. Normally, the automotive air conditioning system consumes about $10 \%$ of the total fuel consumption[23]. Hence, the combined system consumes less fuel than the conventional vapour compression system around $2 \%$. It was also found that, increasing the temperature of the cooling coil cause the compressor to be decreased as same decreasing the temperature of the heating coil or the heat exchanger. 


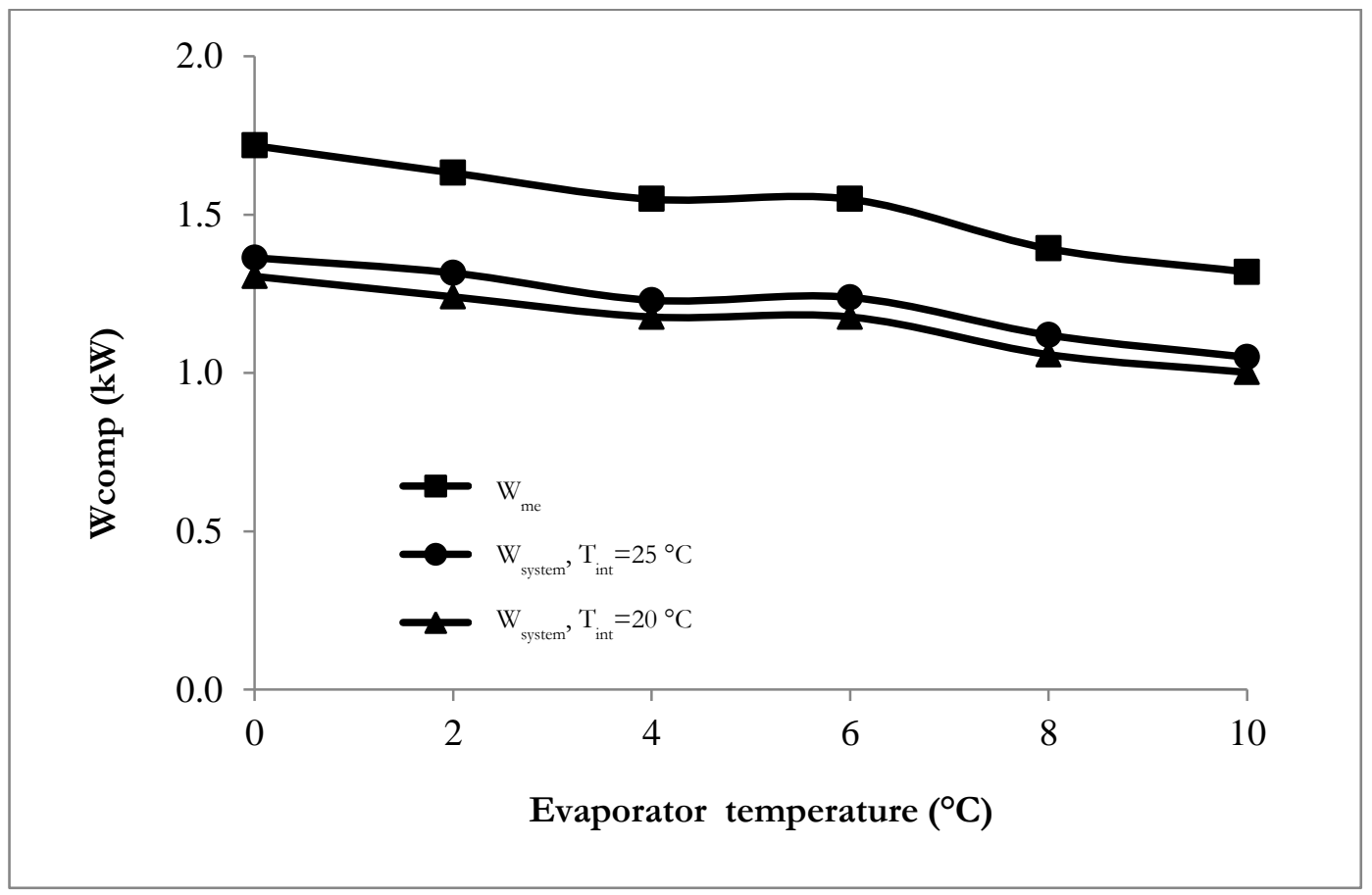

Fig. 15. Variation of input power with evaporating temperature.

\section{Conclusion}

According to the ejector initial area ratio designed by 1-D analysis method for operating conditions with data setup, the influence of generator, evaporator and condenser temperatures on the system performance is researched theoretically. The advantages of the combined ejector cycle over the simple ejector cycle and the conventional vapour compression cycle for automotive air conditioning are able to demonstrate by the results given from the computational model developed for the system. The experiment of an ejector refrigeration cycle combined with a vapour compression cycle for automotive air conditioning results that the entrainment ratio $(\mathrm{Rm})$ of the ejector applying the computational fluid dynamics (CFD) is more suitable compare with 1-D equation due to 1-D equation defines an unknown variable in the equation which possibly affect the entrainment ratio $(\mathrm{Rm})$. The research also found that the hybrid of compressor and ejector for automotive air conditioner is able to reduce power consumption by $20 \%$ compare to the conventional vapor compression system and the COP of the combined system can be increased by $10-20 \%$.

\section{Acknowledgment}

The authors acknowledge the support provided by Office of the Higher Education Commission, the Thailand Research Fund (TRF) and Ubon Ratchathani University.

\section{References}

[1] N. Sharifi and M. Sharifi, "Reducing energy consumption of a steam ejector through experimental optimization of the nozzle geometry,"Energy, vol. 66, pp. 860-867, 2014.

[2] B. Zheng and Y. W. Weng, "A combined power and ejector refrigeration cycle for low temperature heat sources," Solar Energy, vol. 84, pp. 784-791, 2010.

[3] S. Elbel and N. Lawrence, "Review of recent developments in advanced ejector technology," International Journal of Refrigeration, vol. 62, pp. 1-18, 2016.

[4] G. Besagni, R. Mereu, and F. Inzoli, "Ejector refrigeration: A comprehensive review," Renewable and Sustainable Energy Reviews, vol. 53, pp. 373-407, 2016. 
[5] D. Butrymowicz, K. Śmierciew, J. Karwacki, and J. Gagan, "Experimental investigations of lowtemperature driven ejection refrigeration cycle operating with isobutane," International Journal of Refrigeration, vol. 39, pp. 196-209, 2014.

[6] Y. Jia, C. Wenjian, C. Lin, L. Cui, and Y. Li, "Experimental study on performance of a hybrid ejectorvapor compression cycle," Energy Conversion and Management, vol. 113, pp. 36-43, 2016.

[7] C. Li, Y. Li, W. Cai, Y. Hu, H. Chen, and J. Yan, "Analysis on performance characteristics of ejector with variable area-ratio for multi-evaporator refrigeration system based on experimental data," Applied Thermal Engineering, vol. 68, pp. 125-132, 2014.

[8] Y. Zhu and P. Jiang, "Hybrid vapor compression refrigeration system with an integrated ejector cooling cycle," International Journal of Refrigeration, vol. 35, pp. 68-78, 2012.

[9] J. I. Hermandez, R. J. Dorantes, R. Best, and C. A. Estrada, "The behaviour of a hybrid compressor and ejector refrigeration system with refrigerants 134a and 142b," Applied Thermal Engineering, vol. 24, pp. 1765-1783, 2004.

[10] H. Vidal and S. Colle, "Simulation and economic optimization of a solar assisted combined ejectorvapor compression cycle for cooling applications," Applied Thermal Engineering, vol. 30, pp. 478-486, 2010.

[11] J. H. Keenan, E. P. Neumann, and F. Lustwerk, "An investigation of ejector design by analysis and experiment," Transactions of the ASME Journal of Applied Mechanics, vol. 72, pp. 299-309, 1950.

[12] C. Xiangiie, M. Worall, S. Omer, S. Yuehong, and S. B. Riffat, "Theoretical studies of a hybrid ejector $\mathrm{CO}_{2}$ compression cooling system for vehicles and preliminary experimental investigations of an ejector cycle," Applied Energy, vol. 102, pp. 931-942, 2013.

[13] E. Rusly, L. Aye, W. W. S. Charters, and A. Ooi, "CFD analysis of ejector in a combined ejector cooling system," International Journal of Refrigeration, vol. 28, pp. 1092-1101, 2005.

[14] Y. Jial and C. Wenjian, "Area ratio effects to the performance of air-cooled ejector refrigeration cycle with R134a refrigerant," Energy Conversion and Management, vol. 53, pp. 240-246, 2012.

[15] J. LaGrandeur, D. Crane, and A. Eder, "Vehicle fuel economy improvement through thermoelectric waste heat recovery," in Proceedings of the 11th Diesel Engine Emissions Reduction (DEER) Conference, 2005, Chicago, Illinois.

[16] X. Liu, Y. D. Deng, S. Chen, W. S. Wang, Y. Xu, and C. Q. Su, "A case study on compatibility of automotive exhaust thermoelectric generation system, catalytic converter and muffler," Case Studies in Thermal Engineering, vol. 2, pp. 62-66, 2014.

[17] S. M. Ali and A. Chakraborty, "Thermodynamic modelling and performance study of an engine waste heat driven adsorption cooling for automotive air-conditioning," Applied Thermal Engineering, vol. 90, pp. 54-63, 2015.

[18] S. Aphornratana, "Theoretical study of a steam-ejector refrigerator," RERIC International Energy Journal, vol. 18, pp. 61-74, 1996.

[19] T. Thongtip and S. Aphornratana, "An alternative analysis applied to investigate the ejector performance used in R141b jet-pump refrigeration system," International Journal of refrigeration, vol. 53, pp. 20-33, 2015.

[20] ESDU International Ltd., "Ejector and jet pump," Data item 86030, UK, 1985.

[21] W. Hao, C. Wenjian, W. Youyi, Y. Jia, and W. Lei, "Experimental study of the behavior of a hybrid ejector-based air-conditioning system with R134a," Energy Conversion and Management, vol. 112, pp. 31 40, 2016.

[22] A. H. N. Khalifa, J. J. Faraj, and A. K. Shaker, "Performance study on a window type air conditioner condenser using alternative refrigerant R407C," Engineering Journal, vol. 21, no. 1, pp. 235-243, 2017.

[23] C. Christy and R. Toossi, "Adsorption air-conditioning for containerships and vehicles," METRANS Transportantion Centre, Report 00-07, 2004. 